\title{
A PRODUÇÃO DO ETANOL DE SEGUNDA GERAÇÃO A PARTIR DO BAGAÇO DA CANA-DE-AÇÚCAR
}

\author{
Fernanda de Araújo Martins (EPA, UNESPAR-FECILCAM/CAMPO MOURÃO, Brasil) \\ fer_amartins@hotmail.com \\ Thamara Martim (EPA, UNESPAR-FECILCAM/CAMPO MOURÃO, Brasil) thama- \\ ra_martim_@hotmail.com \\ Andressa Maria Corrêa (EPA, UNESPAR-FECILCAM/CAMPO MOURÃO, Brasil) andmari- \\ ah@hotmail.com \\ Faberson Ferreira de Oliveira (EPA, UNESPAR-FECILCAM/CAMPO MOURÃO, Brasil) faber- \\ son_ferreira@hotmail.com
}

\begin{abstract}
Resumo: O presente artigo foi realizado na Universidade Estadual do Paraná (UNESPAR) que tem por objetivo descrever o processo para a produção do etanol de segunda geração, conhecido também como etanol $2 \mathrm{G}$, feito a partir do bagaço da cana-de-açúcar, em que visa o desenvolvimento econômico, social e ambiental do país. Tendo em vista que o país esta investindo em tecnologia para o desenvolvimento do etanol $2 \mathrm{G}$ para minimizar principalmente o uso de combustíveis fósseis, e queimadas que antes era praticado com o bagaço e a palha da cana-de-açúcar. O Brasil tem um grande potencial para este renovado e sustentável "combustível limpo", pois já é um grande produtor em larga escala e baixo custo desta cultura, que se adaptou muito bem ao solo brasileiro. Sendo assim o país precisa investir em tecnologia para produzir o etanol de segunda geração com o custo mais baixo para se tornar viável a produção em larga escala.
\end{abstract}

Palavras-chave: Biocombustível. Sustentável. Biomassa.

\section{Introdução}

No início do século $\mathrm{XX}$, ocorreram as primeiras ações de introdução do etanol na matriz energética brasileira. Em 1925 surgiu a primeira experiência brasileira com etanol combustível (BASTOS, 2007).

Segundo Leite e Cortez (S.D) em 1975 foi lançado o Programa Nacional do Álcool (Proálcool), cujo objetivo maior era a redução da dependência nacional em relação ao petróleo importado, a partir dessa data, ocorreu a substituição da gasolina pelo etanol no Brasil (BASTOS, 2007).

O etanol, também denominado álcool etílico é produzido desde os tempos antigos pela fermentação dos açúcares encontrados em produtos vegetais. Ainda hoje, grande parte do eta- 


\section{ReLAlnEP}

nol industrial é obtido pelo mesmo processo, embora também possa ser produzido a partir de eteno (hidrocarboneto com ligação dupla), derivado do petróleo (BASTOS, 2007).

A partir do etanol feito da cana-de-açúcar (Saccharum) o bagaço era denominado resíduo, sendo ele queimado nas caldeiras para gerar energia, na qual é prejudicial ao ambiente e a saúde humana, devido a poluição gerada (NOGUEIRA, 2008).

Segundo Ramos e Luchiari Jr (2008) a queima do bagaço da cana-de-açúcar nas caldeiras, traz consequências para a população que mora nas proximidades da indústria onde ocorre este processo, causando problemas respiratórios devido à poluição gerada poluição pelas queimadas, sobretudo em crianças e idosos, uma vez que o período de queimada coincide com o período em que a umidade relativa do ar está mais baixa, sendo assim notou-se que o bagaço poderia ser reaproveitado de outra maneira, então realizou-se testes e pesquisas para a elaboração do etanol de segunda geração.

O etanol de segunda geração também conhecido como etanol celulósico pode ser feito a partir do bagaço ou palha da cana-de-açúcar, sorgo, milho, beterraba, entre outros, porém, o mais comum é o feito a partir do bagaço e da palha da cana-de-açúcar (NOGUEIRA, 2008). É visto como uma alternativa para ampliar a produção do álcool no Brasil, sem ter de investir diretamente em aumento da área e de matéria-prima, por conta do aproveitamento de resíduos como, por exemplo, a palha e o bagaço da cana (UNICA, 2013).

Segundo a Braskem (2013), a cana-de-açúcar é um exemplo de cultura renovável e versátil, que pode ser utilizada como fonte de energia limpa e matéria-prima de produto. O Brasil hoje é o maior produtor mundial de cana-deaçúcar. A modernização das 430 usinas em operações no país, com a doação de novas tecnologias, desde o plantio até a produção de açúcar, etanol e bioeletricidade, fortalecem o setor, reconhecido mundialmente por seu pioneirismo e sua eficiência produtiva.

A produtividade média de cana-de-açúcar está em torno de $74.100 \mathrm{~kg} / \mathrm{ha}$ (CONAB, 2013). Sendo que para cada tonelada de cana-deaçúcar tem-se em média $250 \mathrm{~kg}$ de bagaço. (UNICA, 2008). As vantagens atribuídas para o uso do bagaço e pontas de cana-de-açúcar são estimadas que eleve a produção de álcool em 30 a 40\%, para uma mesma área plantada, portanto, não é necessário que se expanda as áreas de produção para o desenvolvimento do produto, por isso se torna viável a sua produção (PACHECO, 2011).

Segundo Pacheco (2011), o mercado consumidor de etanol crescerá ainda mais, tanto nacional quanto mundialmente, em um futuro próximo, devido às legislações ambientais que obrigam o uso de biocombustíveis em meios de transporte.

O Brasil tem potencial para produzir o etanol de segunda geração feito através do bagaço da cana-de-açúcar em larga escala, pois há matéria-prima em abundância com fácil acessibilidade, sendo capaz de competir com outros países. Desta forma tem-se necessidade de aprofundar-se nos estudos e pesquisas dos processos para obtenção deste novo biodiesel, 
em que pode ser uma das alternativas mais promissoras e ambientalmente sustentáveis para a substituição de combustíveis fósseis. Logo, foram realizadas pesquisas com o intuito de descrever o processo de produção do etanol de segunda geração, feito a partir do bagaço da cana. Observou-se que são necessárias novas pesquisas para o aperfeiçoamento desta tecnologia. Essa nova geração representa uma alternativa para o uso energético da biomassa, tendo em vista que apresenta vantagens ambientais e econômicas, por ser o etanol produzido do bagaço, na qual há um reaproveitamento da matéria-prima e o aumento da produção sem a expansão da área de produção.

\section{Metodologia}

A pesquisa foi realizada na Universidade Estadual do Paraná (UNESPAR/FECILCAMCampus Campo Mourão), no período de agosto à setembro de 2013.

Sendo que o método de abordagem utilizado foi o qualitativo. A pesquisa caracteriza-se quanto aos fins como explicativa e quanto aos meios, como bibliográfica e virtual.

A revisão de literatura foi realizada consultando alguns dados da União da Indústria de Cana de açúcar (UNICA).

E alguns levantamentos sobre produção e produtividade na Companhia Nacional de Abastecimento (CONAB).

Foram realizadas pesquisas sobre o mercado de consumidores potenciais do Etanol 2G no La- boratório Nacional de Ciência e Tecnologia do Bioetanol (CTBE, 2013).

Leite e Cortez explicam que o Brasil pode diminuir drasticamente o uso de combustíveis fósseis, por um combustível limpo diminuindo assim o aquecimento global.

Segundo a CTBE (2013), o Brasil e a Europa se unem para realizar pesquisas para o desenvolvimente de tecnologias que possam diminuir o custo da produção do álcool de segunda geração a partir da biomassa da cana-deaçúcar.

Dessa forma, o presente artigo será estruturado segundo as ideias dos autores e instituições citados anteriormente.

\section{Processo da obtenção do etanol de se- gunda geração}

As tecnologias avançadas de obtenção de etanol de segunda geração encontram-se em desenvolvimento. A rigor, não existe nenhuma unidade que produza em escala comercial (NOGUEIRA, 2008).

Segundo Santos et al. (2012) a composição química da biomassa lignocelulósica, geralmente contém $35-50 \%$ de celulose, seguido de 20-35\% de hemicelulose, $10-25 \%$ de lignina e uma pequena quantidade de cinzas e extrativos. Esta composição química varia em função do tipo de biomassa, conforme mostra a Tabela 1. 
TABELA 1: COMPOSIÇÃO DA BIOMASSA LIGNOCELULÓSICA (\% EM BASE SECA)

\begin{tabular}{|c|c|c|c|c|}
\hline & Eucalipto & Pinheiro & Switch-grass* & Bagaço \\
\hline Celulose & 49,5 & 44 & 32 & 37 \\
\hline Hemicelulose & 13 & 22 & 25 & 28 \\
\hline Lignina & 27,5 & 28 & 18 & 21 \\
\hline Outros & 10 & 5,5 & 24 & 14 \\
\hline
\end{tabular}

Segundo Medeiros (1992) o bagaço de canade-açúcar in natura é definido como resíduo dos colmos da cana-de-açúcar, resultado da extração máxima do conteúdo celular rico em açúcares solúveis. Portanto, o bagaço de canade-açúcar reúne fragmentos grosseiros da parede celular e conteúdo celular não extraído na moagem da cana-de-açúcar. Cujo componente principal é representado pelo açúcar não extraído durante o processo de moagem, aproximadamente 2 a $3 \%$, e alto teor de componentes da parede celular (carboidratos estruturais), em torno de 70 a $85 \%$, dos quais a celulose é o principal (44 a 50\%), seguida da hemicelulose (24 a 30\%) e da lignina (10 a 20\%).

Sendo a lignina, celulose e hemicelulose estruturadas conforme a Figura 1.

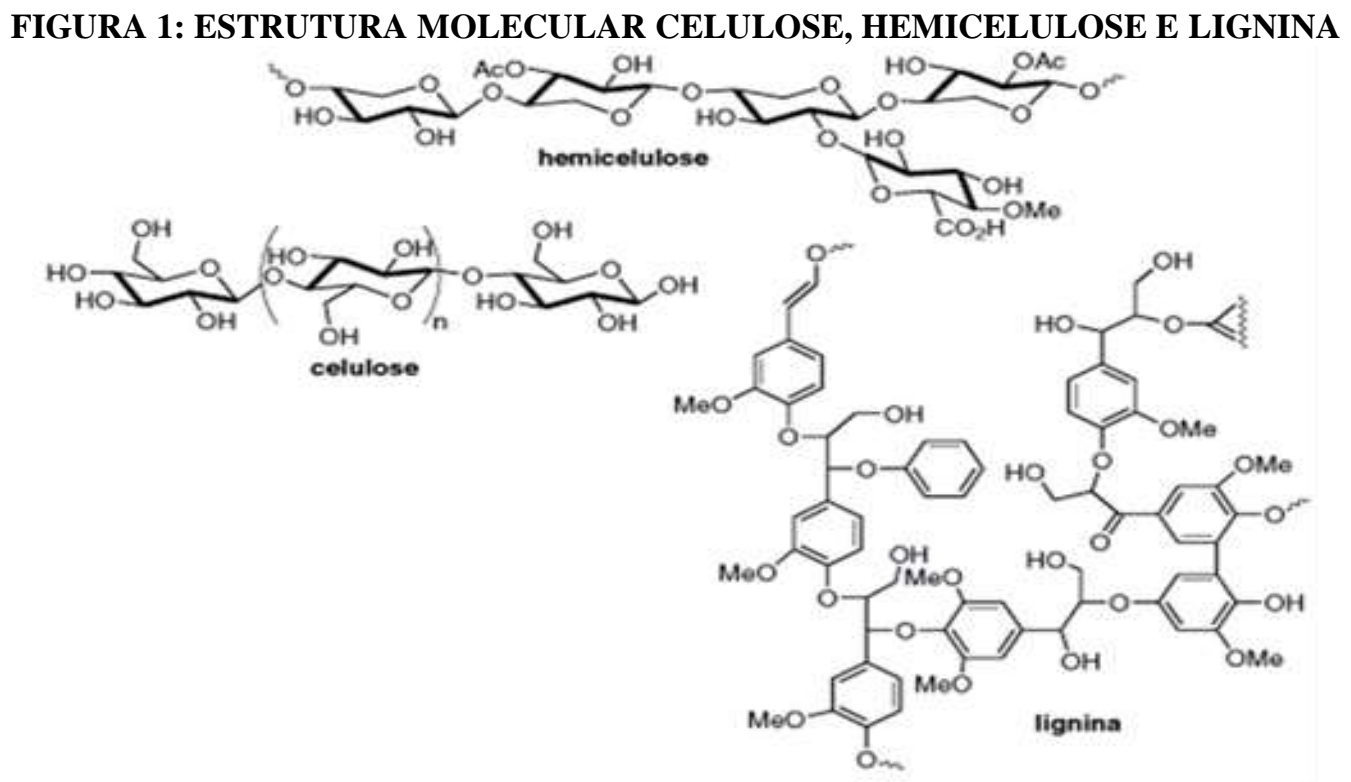

Fonte: Ferreira et al (2009)

- Celulose

A celulose (C6H10O5) principal componente da parede celular da fibra vegetal é um polímero de cadeia longa composto de um só monô- mero (glicose) e por isso classificado como homopolissacarídeo. É a matéria orgânica mais abundante sobre a Terra, consistindo aproximadamente em $50 \%$ de toda a biomassa e uma produção anual de cerca de 100 bilhões de toneladas (YANG et al., 2007). 


\section{ReLAInEPY}

- Hemicelulose

Outro componente essencial na parede celular das plantas são as hemiceluloses. Estas macromoléculas estão intimamente ligadas à celulose, definindo propriedades à parede celular e desempenhando funções de regulação do crescimento e desenvolvimento das plantas (FENGEL; WEGENER, 1991; LIMA; RODRIGUES, 2007). As hemiceluloses são polissacarídeos formados por diferentes unidades de açúcares pertencentes aos grupos das pentoses, hexoses, ácidos hexourônicos e desoxiexoses.

\section{- Lignina}

Uma das substâncias orgânicas macromoleculares naturais é a lignina, que ocupa cerca de $30 \%$ dos carbonos da biosfera (FENGEL; WEGENER, 1991). Sua estrutura é bastante heterogênea e consiste em uma rede de anéis aromáticos unidos, principalmente por ligações alquil-aril-éter, formando um arranjo amorfo com grandes quantidades de ligações cruzadas entre os anéis aromáticos (ARGYROPOULOS; MENACHEM, 1997).
As normativas para o etanol de segunda geração, não foram formuladas, pois o mesmo está em fase de teste, em que se estima que para 2016 será permitido a comercialização do etanol de segunda geração (RAPOSO, 2013).

\section{Etapas para a obtenção do etanol a partir da biomassa}

Para a obtenção do etanol segunda geração através da biomassa é precisso que o bagaço passe por alguns processos, sendo eles: prétratamento; hidrólise; fermentação; e purificação, obtendo o produto final. De acordo com a Figura 2, nota-se que na obtenção do etanol de segunda geração existem algumas etapas a mais que o etanol de primeira geração, sendo elas o pré-tratamento da biomassa, e a outra etapa é a hidrólise. Observa-se que o etanol de segunda geração obtido através do bagaço da cana-de-açúcar tem um custo maior do que o etanol convencional produzido do caldo da cana-de-açúcar.

\section{FIGURA 2: FLUXOGRAMA PARA OBTENÇÃO DO ETANOL DE SEGUNDA GERAÇÃO A PARTIR}

DA BIOMASSA

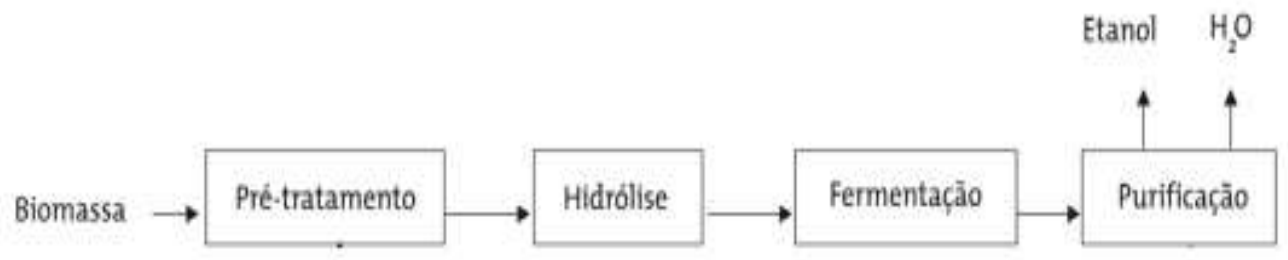

Fonte: Hamelinck et al. (2005) 


\section{ReLAInEP}

\subsubsection{Pré-tratamento}

A conversão da maioria dos materiais lignocelulósicos em álcool a partir da celulose requer pré-tratamento antes da hidrólise (como pode ser observado pela Figura 2). O objetivo do pré-tratamento é remover a hemicelulose e a lignina, reduzir a cristalinidade da celulose e aumentar a porosidade dos materiais; além disso, deve evitar a degradação ou perda de carboidratos e a formação de bioprodutos que possam inibir os microrganismos fermentadores. Existem diversos tipos de pré-tratamentos, com diferentes rendimentos e efeitos distintos sobre a biomassa e conseuqente impacto nas etapas subsequentes (McMILLAN, 1994).

O Quadro 1 mostra as principais práticas de pré-tratamento, que estão sendo utilizadas e aperfeiçoadas.

QUADRO 1: MÉTODOS DE PRÉ- TRATAMENTO

\begin{tabular}{|c|c|c|c|}
\hline Processo & Descrição & $\begin{array}{l}\text { Tempo de reação } \\
(\min )\end{array}$ & $\begin{array}{l}\text { Rendimento } \\
\text { de xilose* } \\
(\%)\end{array}$ \\
\hline \multicolumn{4}{|c|}{ FÍSICOS } \\
\hline $\begin{array}{l}\text { Explosão de } \\
\text { Vapor }\end{array}$ & $\begin{array}{l}\text { A biomassa é triturada e tratada com vapor (saturado } \\
160^{\circ}-260 \text { ) seguindo de uma rápida descompressão. }\end{array}$ & $1-10$ & $45-65$ \\
\hline $\begin{array}{l}\text { Termo- } \\
\text { hidrólise }\end{array}$ & $\begin{array}{l}\text { Utiliza água quente a alta pressão (pressões acima } \\
\text { do ponto de saturação) para hidrolisar a hemicelulo- } \\
\text { se }\end{array}$ & 30 & $88-98$ \\
\hline \multicolumn{4}{|c|}{ QUÍMICOS } \\
\hline $\begin{array}{l}\text { Hidrólise } \\
\text { ácida }\end{array}$ & $\begin{array}{l}\text { Por meio do uso de ácidos sulfúrico, clorídrico ou } \\
\text { nítrico, concentrados ou diluídos. }\end{array}$ & $2-10$ & $5-90$ \\
\hline Organosolv & $\begin{array}{l}\text { Uma mistura de um solvente orgânico (metanol, } \\
\text { bioetanol e acetona, por exemplo) com um catalisa- } \\
\text { dor ácido }\left(\mathrm{H}_{2} \mathrm{SO}_{4}, \mathrm{HCl}\right) \text { é usada para quebrar as } \\
\text { ligações internas da lignina e da hemicelulose. }\end{array}$ & $40-60$ & $70-80$ \\
\hline
\end{tabular}

Fonte: Adaptado de Hamelinck et al. (2005); BNDES (2008), e Alvira et al. (2010)

\subsubsection{Hidrólise da Biomassa}

Existem basicamente três técnicas para a obtenção de açúcares fermentescíveis provenientes de matérias lignocelulósicos: hidrólise com ácido concentrado, hidrólise com ácidos diluídos e hidrólise enzimática.

A etapa de hidrólise (sacarificação) (Tabela 2) tem como objetivo a redução das macromolé- culas de celulose e de hemicelulose, através da adição de ácido sulfúrico aos resíduos, para que seja feita uma hidrólise ácida, ou por meio da ação de enzimas, hidrólise enzimática para obter açúcares fermentescíveis. 
TABELA 2: PROCESSOS DE HIDRÓLISE (SACARIFICAÇÃO) DE MATERIAL LIGNOCELULÓSICO

\begin{tabular}{ccccc}
\hline Processo & Insumo & $\begin{array}{c}\text { Temperatura } \\
\left({ }^{\circ} \mathbf{C}\right)\end{array}$ & $\begin{array}{c}\text { Tempo } \\
(\mathbf{m i n})\end{array}$ & $\begin{array}{c}\text { Sacarificação } \\
(\%)\end{array}$ \\
\hline Ácido diluido & $<1 \% \mathrm{H}_{2} \mathrm{SO}_{4}$ & 215 & 3 & $50-70$ \\
Ácido concentrado & $30 \%-70 \% \mathrm{H}_{2} \mathrm{SO}_{4}$ & 40 & $120-360$ & 90 \\
Enzimático & Celulase & 70 & 2160 & $75-95$ \\
\hline
\end{tabular}

Fonte: BNDS (2008)

O processo com ácido diluído utiliza altas temperaturas e pressões, com tempos de reação de segundos a minutos, o que facilita o uso de processos contínuos. Já os processos com ácido concentrado são conduzidos em condições mais brandas de temperatura, mas com tempos de reação mais longos (GRAF; KOEHLER, 2000).

No processo enzimático, a hidrólise é catalisada por um complexo de enzimas caracterizado comercialmente como celulases compostas por endoglucanases (que agem especificamente na catálise da hidrólise das cadeias de celulose produzindo polissacarídeos de menor comprimento), exoglucanases (que catalisam especificamente as extremidades não redutoras dessas cadeias mais curtas, originando a celobiose) e B-glucosidases (que catalisam a hidrólise da celobiose e outros oligômeros à glicose) (NOVOZYMES, 2002).

O processo de hidrólise pela via enzimática é conduzido em condições brandas de processo, com pH 5,0 e temperatura por volta de $50^{\circ} \mathrm{C}$, o que reduz os custos operacionais, além de conferir maior rendimento, possibilitar a fermentação simultânea à sacarificação (processo SSF simultaneous saccharification and fermenta- tion) e apresentar baixo custo de manutenção das instalações.

Por conta de seu grande potencial de evolução e menor custo, muitos especialistas indicam a hidrólise enzimática como a mais promissora para a produção de bioetanol, com um custo competitivo em longo prazo (DIPARDO, 2000).

A hidrólise com ácido concentrado apresenta rendimentos pouco maiores, mas a necessidade de recuperação do ácido e o uso de equipamentos resistentes à corrosão comprometem o desempenho econômico do processo (BNDS, 2008).

\subsubsection{Fermentação}

Existem dois tipos de fermentação, a fermentação do material lignocelulósico, e a fermentação dos carboidratos. Ambos obtidos a partir da hidrólise.

\subsubsection{Fermentação alcoólica dos carboi- dratos obtidos da hidrólise}

Para as glicoses o processo de fermentação é feito com a levedura Saccharomyces cerevisiae. Nesse processo obtêm-se dois tipos de açúcares, a glicose e as pentoses. As leveduras 


\section{ReLAInEPY}

fermentam açúcares, produzindo álcool etílico e gás carbônico (CO2), processo denominado fermentação alcoólica. Na fermentação alcoólica, as duas moléculas de ácido pirúvico produzidas são convertidas em etanol, com a liberação de duas moléculas de $\mathrm{CO} 2$ e a formação de duas moléculas de ATP, conforme a Figura 3.

\section{FIGURA 3: PROCESSO DE FERMENTAÇÃO}

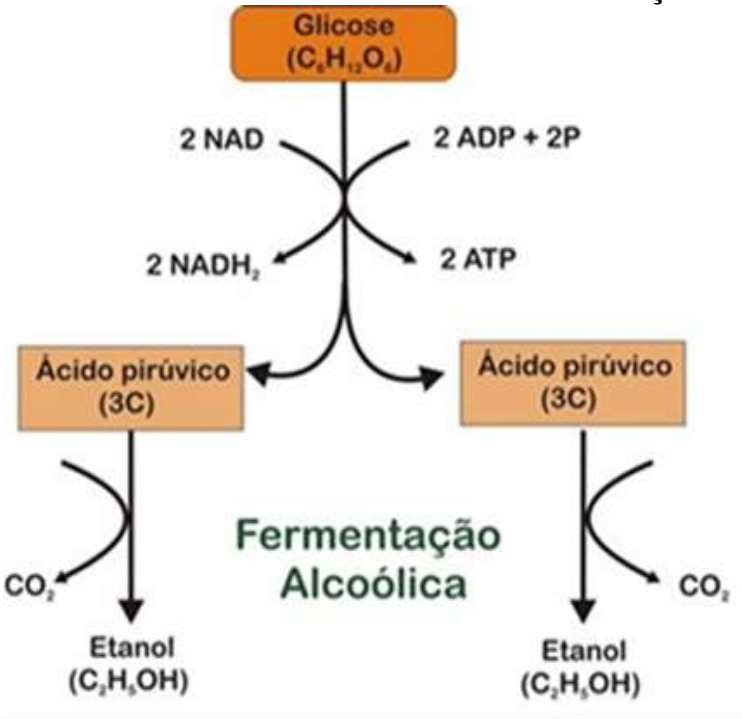

Fonte: Só biologia (S.D.)

A dificuldade na etapa de fermentação consiste na biotransformação das pentoses. A transformação das pentoses em bioetanol é fundamental para a eficiência do processo a partir da lignocelulósica.

As linhas de pesquisa em andamento estão centradas em: seleção e melhoramento de leveduras que fermentem naturalmente as pentoses a etanol; desenvolvimento de linhagens recombinantes de Saccharomyces cerevisiae; seleção de bactérias termofílicas (Thermoanaerobacter ethanolicus); seleção de bactérias mesófilas (Zymomonas mobilis, Escherichia colie e Klebsiella.).
Três espécies de leveduras são identificadas como as de maior potencial para a fermentação alcoólica das pentoses, são elas: Pichia stipitis, Candida shehatae e Pachysolen tannophilus, porém com desempenho até o momento muito limitado.

\subsubsection{Fermentação alcoólica do material} lignocelulósico resultante da hidrólise

Os materiais lignocelulósicos, quando hidrolisados produzem hexoses oriundas da celulose que são facilmente fermentadas pelos microorganismos (leveduras). Já a hidrólise da hemicelulose fornece pentoses (xilose e arabinose), que não são diretamente fermentadas por leveduras industriais convencionais, sendo a biotransformação dessas pentoses, a etanol um dos desafios mais importantes a resolver no âmbito científico e tecnológico (ROSSELL, 2000).

A hidrólise da hemicelulose produz também hexoses tais como glicose, manose e galactose, sendo que esta última exige linhagens de levedura específicas para produção de etanol.

Em função das altas temperaturas e condições ácidas em que se desenvolvem os prétratamentos e a hidrólise ácida da matériaprima lignocelulósica, originando compostos cuja natureza e a concentração depende do tipo de matéria-prima, do pré-tratamento utilizado, das condições do processo (temperatura e tempo de reação) e do emprego de catalisadores ácidos, que irão atuar como inibidores da fermentação (LUDVIG, 2012). 


\section{ReLAInEPI}

\section{Purificação}

É uma operação que permite a separação de misturas de líquidos em componentes puros próximos de pureza e que se realiza a vaporização e condensação sucessivas à operação em questão é exequível quando se verifica uma diferença de volatilidade entre os componentes do líquido (RASOVSKY, 2009).

A destilação fracionada ocorre por meio de vaporização e condensações sucessivas por meio das diferentes volatilidades das substâncias (RASOVSKY, 2009). A alimentação é introduzida no meio da coluna descendo até atingir o refervedor (trocador de calor aquecido por vapor), onde entrará em ebulição. Este vapor ascenderá à coluna em contra corrente com a alimentação atingindo o condensador onde será liquefeito (RASOVSKY, 2009).

\subsection{Tronco de destilação $A$}

É caracterizado pela sobreposição das 03 colunas descritas a seguir:

Coluna A - conhecida como coluna de esgotamento do vinho, possui de 15 a 20 bandejas, produzindo uma flegma de 35 a $65^{\circ}$ GL e como subproduto a vinhaça. Nesta coluna figura III é admitido o vapor para o aquecimento do tronco de destilação (EBA CONSULTORIA, 2008).

Coluna A1 - composta por 08 bandejas, onde é feita a elevação do teor alcoólico e a epuração do vinho que consiste na evaporação dos produtos mais voláteis. Nesta coluna o vinho é admitido no aparelho (EBA CONSULTORIA, 2008).
Coluna D - composta de 06 bandejas sobrepostas à coluna A1 e separada por uma bandeja cega. A interligação destas colunas é feita por uma tubulação em forma de "U”. Sua função é concentrar o álcool de segunda (EBA CONSULTORIA, 2008).

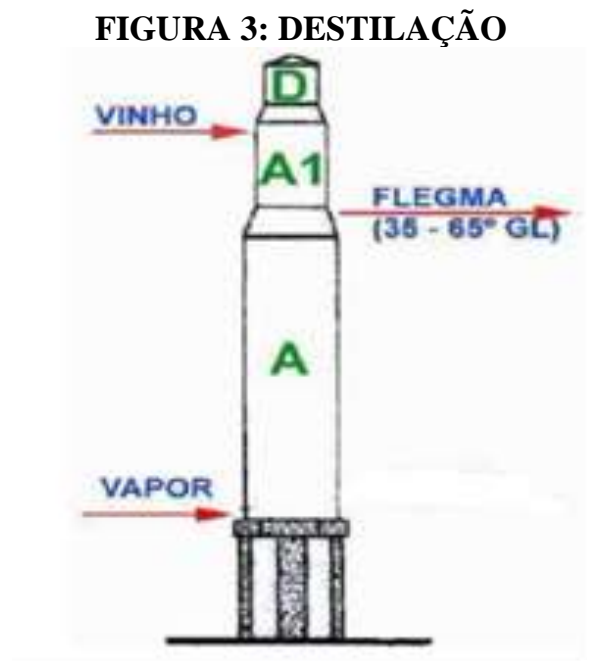

Fonte: EBA Consultoria (2008)

\subsection{Tronco de retificação $B$}

O tronco retificador se caracteriza por apresentar uma coluna de esgotamento (B1) e uma coluna de concentração (B). Nesta coluna (Figura 4) o flegma é concentrado de $86-97^{\circ} \mathrm{GL}$. A admissão de vapor é feita na base da coluna B1, garantindo a pressão e temperatura necessárias em todo o tronco (EBA CONSULTORIA, 2008). 


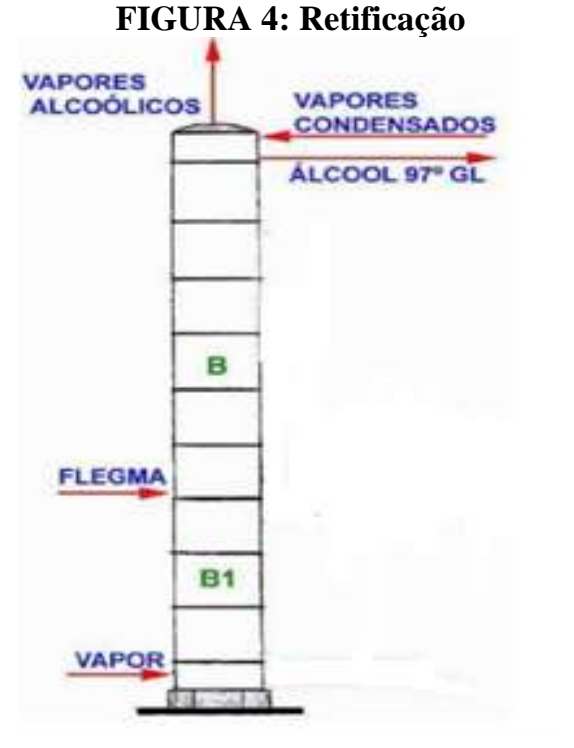

Fonte: EBA CONSULTORIA (2008)

\section{Considerações Finais}

Como o etanol é um combustível renovável, que tem participação relevante em relação aos combustíveis fósseis, assim aumentando a sua procura. Com o crescimento desse combustível no mercado uma maior produção tem que ser levada em conta, para suprir eventuais demandas e substituir os combustíveis fósseis, e uma das alternativas é o etanol de segunda geração. Ele é feito através de biomassa da cana-de-açúcar ou de outras fontes de matérias que tenha celulose.

O etanol de segunda geração é uma alternativa que proporcionará um desenvolvimento econômico, social e ambiental. Pois, no Brasil a produção da cana-de-açúcar é elevada, e aproveitando este privilégio o país está investindo em novas tecnologias, para o que antes era considerado resíduo ou usado como fonte energia para as caldeiras se torne uma nova fonte de energia limpa, reaproveitando o baga- ço e a palha da cana-de-açúcar, para a produção do etanol 2G. Porém essa tecnologia tem que ser mais elaborada, desenvolvida e pesquisada, pois a mesma tem um custo elevado, mas é viável pelos benefícios quanto á sustentabilidade e quanto à matéria-prima que se tem em grande escala.

Este biocombustível não está sendo produzido em escala comercial, pois ainda está em fase de testes, portanto ainda não há normativas específicas para o mesmo. Sendo assim é usado como parâmetro as normativas do etanol de primeira geração.

\section{Referências}

BRASKEM. I'm green. A cana de açúcar, São Paulo, 2013. Disponível em: < http:/ /www.braskem.com.br/site.aspx/Canade-Acucar\#rio06> Acesso em: 24 ago. 2013.

AGÊNCIA NACIONAL DO PETRÓLEO. Resolução do ANP $\mathbf{N}^{\circ}$ 7, de 9.2.2011 - DOU 10.2.2011 - RETIFICADA DOU 14.4.2011. Disponível em:<http://nxt.anp.gov.br/nxt/gateway.dll/le g/resolucoes_anp/2011/fevereiro/ranp $\% 207 \%$ 20-\%202011>. Acesso em 31 ago. 2013.

ALVIRA, P.; TOMÁS-PEJÓ, E.; BALLESTEROS, M.; NEGRO, M. J. Pretreatment technologies for an efficient bioethanol production process based on enzymatic hydrolysis: a review. Bioresource Technology, v. 101, n. 13, p. 4851486, 2010.

ARGYROPOULOS D. S. \& MENACHEM S. B. Lignin. Advances in Biochemical Engineering Biotechnology, v. 57, p. 127-158, 1997.

BNDS. Banco Nacional De Desenvolvimento Econômico E Social. Bioetanol de cana-de-açúcar: energia para o desenvolvimento sustentável. Rio de Janeiro, 2008, 316p.

BASTOS, V. D. Etanol, alcoolquímica e biorrefinarias. BNDES/Setorial, São Paulo, 2007. Disponível em: $<$ http://homologa.ambiente.sp.gov.br>. Aces- 
so em 5 set. 2013.

CONAB. Companhia Nacional De Abastecimento. Cana-de-açúcar, 2013. Disponível em: $<$

http: / /www.conab.gov.br/OlalaCMS/uploads / arqui-

vos/13_08_08_09_39_29_boletim_cana_portu gues_-_abril_2013_1o_lev.pdf > Acesso em: 10 ago. 2013

DIPARDO, J. Outlook for biomass ethanol production and demand. Washington, D. C.: U. S. Department of Energy - Energy Information Administration, 2000. p.12.

EBA CONSUlTORIA. Treinamento e processos de fabricação do etanol. Usina Da Mata. 2008.

FENGEL, D. \& WEGENER, G. Wood and cellulosic chemistry. New York, p. 189-200, 1991.

FERREIRA, V. F.; ROCHA, D. R. da.e SILVA, F. de C. da. Potencialidades e oportunidades na química da sacarose e outros açúcares. São Paulo, 2009. Disponível em: <http: / / www.scielo.br/scielo.php?pid=S010040422009000300007\&script=sci_arttext\#nt>. Acesso em: 2 set. 2013.

GERON, L. J. V. et al. Composição química, valor de ph e temperatura do bagaço de cana-de-açúcar in natura e hidrolisado com cal (cao) conservados em mini silos. Revista de Ciências Agroambientais, Alta Floresta, n., p.59-68, 2010.

GRAF, A.; KOEHLER, T. Oregon celluloseethanol study: an evaluation of the potential for ethanol production in Oregon using cellulose-based feedstocks. Salem: Oregon Office of Energy, 2000.

HAMELINCK, C. N. et al. Etanol from lignocellulosic biomass: technoeconomic performance in short, middle and long term. Biomass and Bioenergy 28 (2005), 384-410. Disponível em: <http://www.star-

in-

fo/pdf/bdocs/transport/Bioethanol_Biomass.pd f. $>$.

HORTA NOGUEIRA, L. A. et al. Bioetanol de cana-de-açúcar: energia para o desenvolvimento sustentável. Rio de Janeiro: BNDES,
2008.

CTBE. Laboratório Nacional De Ciência E Tecnologia Do Bioetanol. Brasil e Europa se unem pelo etanol de segunda geração, 2013. Disponível em: $<$

http:/ /www.bioetanol.org.br/noticias/detalhe. php>. Acesso em 17 de ago. 2013.

LEITE, C. R. et al. O etanol combustível no Brasil. Acesso em: 21 ago. 2013.

LIMA, A. O. S. \& RODRIGUES, A. L. Sacarificação de resíduos celulósicos com bactérias recombinantes como estratégia para redução do efeito estufa. Revista de ciências ambientais, v. 1, n. 2, p. 5-18, 2007.

LUDVIG, D. Produção de álcool combustível a partir de hidrolisados enzimáticos de bagaço de cana-de-açúcar por leveduras industriais e leveduras fermentadoras de xilose. Florianopolis-SC, 2010. Disponível em: $<$ https: / / repositorio.ufsc.br/handle/12345678 9/94591>. Acesso em: 4 set. 2013.

McMillan, J. D. In Enzymatic Conversion of Biomass for Fuels Production. HIMMEL, M. E.; BAKER, J. O.; OVEREND, R. A. eds., ACS Symposium Series 566, American Chemical Society, Washington, DC, p. 411-437, 1994.

NOVOZYMES. Fuel ethanol production: technological and environmental improvements. [S. 1.]: Novozymes \& BBI International, 2002.

PACHECO, F. T. Produção de etanol: primeira ou segunda geração? . Circular Técnica. Abril 2011. Disponível em: < http:/ / www.infoteca.cnptia.embrapa.br/bitstre am/doc/886571/1/CITE04.pdf $>$ Acesso em: 13 ago. 2013.

RAMOS, N. P.; LUCHIARI, J. A árvore do conhecimento. Cana-de-Açucar: Impactos ecológicos. Disponível em: $<$ http://www.agencia.cnptia.embrapa.br/gesto r/cana-de-acucar/arvore/CONT1.html>. Acesso em: 30 ago. 2013.

RAPOSO, P. Etanol 2G para exportação. Pernambuco, 2013. Disponível em: < http: / / www.novacana.com/n/etanol/2geracao-celulose/ etanol-2g-sera-paraexportacao-110913/\#>. Acesso em: 02 set. 2013.

RASOVSKY, E. M. Álcool: Destilarias, Instituto 
do Açúcar e do Álcool. Rio de Janeiro: Coleção Canavieira, 2009.

ROSA, S. E. S. da; GARCIA, J. L. F.. O etanol de segunda geração: limites e oportunidades. Revista do BNDES, Rio de Janeiro, n. 32, p.117156, 07 ago. 2009. Dezembro. Disponível em: <http://www.bndes.gov.br/SiteBNDES/expor t/sites/default/bndes_pt/Galerias/Arquivos/co nhecimento/revista/rev3204.pdf>. Acesso em: 30 ago. 2013.

ROSSEll, C. E. V., Fermentação do Hidrolisado. Campinas-SP, 2000. Disponível em: $<$ www.apta.sp.gov.br/cana/anexos/PPaper_ses sao_3_Rossell.pdf>. Acesso em: 3 set. 2013.

SANTOS, F. A; QUEIRÓZ, J. H. de; COLODETTE, J. L. et al. Potencial da palha de canade-açúcar para produção de etanol. São Paulo, 2012. Disponível em: $<$ http://www.scielo.br/scielo.php?script=sci_a rttext\&pid=S0100-40422012000500025>.

Acesso em: 3 set. 2013.

SILVA, P. R. Produção de etanol a partir da biomassa florestal. Embrapa, pesquisa agropecuária, inovação e qualidade de vida, 2012.

YANG, H.; YAN, R.;CHEN, H.; LEE, D., H.; ZHENG, C. Characteristics of hemicelluloses, cellulose, and lignin pyrolysis. Fuel, v. 86, p. 1781-1788, 2007. 